\title{
Development of low cost agarwood essential oil extraction system for agar tree growers in Bangladesh
}

\author{
M. A. Islam*, M. D. Hussain, E. Kabir and M. Z. Hasan \\ Department of Farm Power and Machinery, Bangladesh Agricultural University, Mymensingh-2202, Bangladesh, \\ *E-mail: aktarul.bau@gmail.com
}

\begin{abstract}
This experiment was conducted to bring in a suitable and economic agarwood oil extraction method for Agar tree (Aquilaria agollocha) growers in Bangladesh. Agarwood was collected from Fotikchori upazila of Chittagong district and a prototype of hydro-distillation extraction chamber was developed at the lab of Department of Farm Power and Machinery, Bangladesh Agricultural University, Mymensingh, Bangladesh during January to March 2013. Using the prototype, $7 \mathrm{ml}$ of agarwood oil was extracted from $15 \mathrm{~kg}$ matured agarwood. It was found from the calculation that the developed system can bring yearly benefit of Tk. 7,78,389 with benefit-cost ratio as 2.33 . This development was, therefore, proven very beneficial for Bangladeshi agar tree growers.
\end{abstract}

Keywords: Agar tree, Agarwood, Oil extraction, Low cost, Hydro-distillation

\section{Introduction}

Agar, eaglewood, gaharu and aloeswood are alternative names for the resinous, fragrant and highly valuable heartwood produced by Aquilaria agallocha Roxb. (Thymelaceae) and other species of the tree genus Aquilaria. Agarwood is extremely highly valued by luxury perfume, fragrance and soap manufacturers. Both agarwood smoke and oil are customarily used as perfume in the Middle East (Barden et al., 2000). There are fifteen species in the genus Aquilaria and eight are known to produce agarwood ( $\mathrm{Ng}$ et al., 1997). In theory agarwood can be produced from all members; however, until recently it was primarily produced from $A$. malaccensis, $A$. agallocha and $A$. secundaria (Broad, 1995). Occasionally the heartwood gets infected by a mold, Phaeoacremonium parasitica (Gibson, 1977). As a response, the tree produces a resin high in volatile organic compounds that aids in suppressing or retarding the fungal growth. Oldfield et al. (1998) stated that resin production is in response to fungal infection. There are few small scale and personal agarwood plantations in Sylhet, Habiganj and Chittagong Hill Tracks in Bangladesh (Akter et al., 2013). Agarwood oil extraction is done at some industries in Bangladesh, but the extraction processes are very complex, comprising of expensive mechanical, solvent extraction and cold processing system. In this context, the developed hydro distillation method is much more suitable for the cultivators of Bangladesh economically and technologically. Therefore, this experiment was carried out to develop a low cost hydro distillation system for agarwood oil extraction, to determine production by the developed system and to calculate economic benefits by it.

\section{Materials and Methods}

\section{Experimental site and period}

Matured agarwood was collected from Fotikchori Upazila of Chittagong district and the hydro-distillation extraction model was developed at the Farm Power and Machinery Department Lab of Bangladesh Agricultural University, Mymensingh during January-March, 2013.

\section{Collection of wood}

A matured, artificially inoculated tree of about 15 years old was selected after observing the color of the wood by peeling off the bark. The selected tree was cut down and $15 \mathrm{~kg}$ matured woods were collected for the experiment. 


\section{Chopping}

Woods were chopped using a sharp, heavy knife into 2 to 3 inches long and 0.5 to 1 inch thin pieces for fermentation.

\section{Fermentation}

Chopped woods were soaked in water in a steel drum. The water level was 3 inches above the wood layer and it was left for 40 days for fermentation. After fermentation wood chips turned black, soft and smelly. Water was also preserved for the next steps of processing.

\section{Construction of the extraction chamber}

\section{Materials used}

The prototype (Fig. 1) was made by locally available cheap materials procured from local market. The materials used to construct the extraction chamber were- steel pipe $\left(1^{\prime \prime}, 1 / 2^{\prime \prime}\right.$ and $1 / 4^{\prime \prime}$ dia.), steel flat sheet (16 SWG), C clamp, angles of steel pipe, pan, brick, polythene and gas burner.

\section{Dimensions of heating chamber}

Pan diameter $=27$ inches

Pan height $=18$ inches

Oven height $=36$ inches

C clamp $=1.5$ inch (height)

\section{Dimensions of condensation chamber}
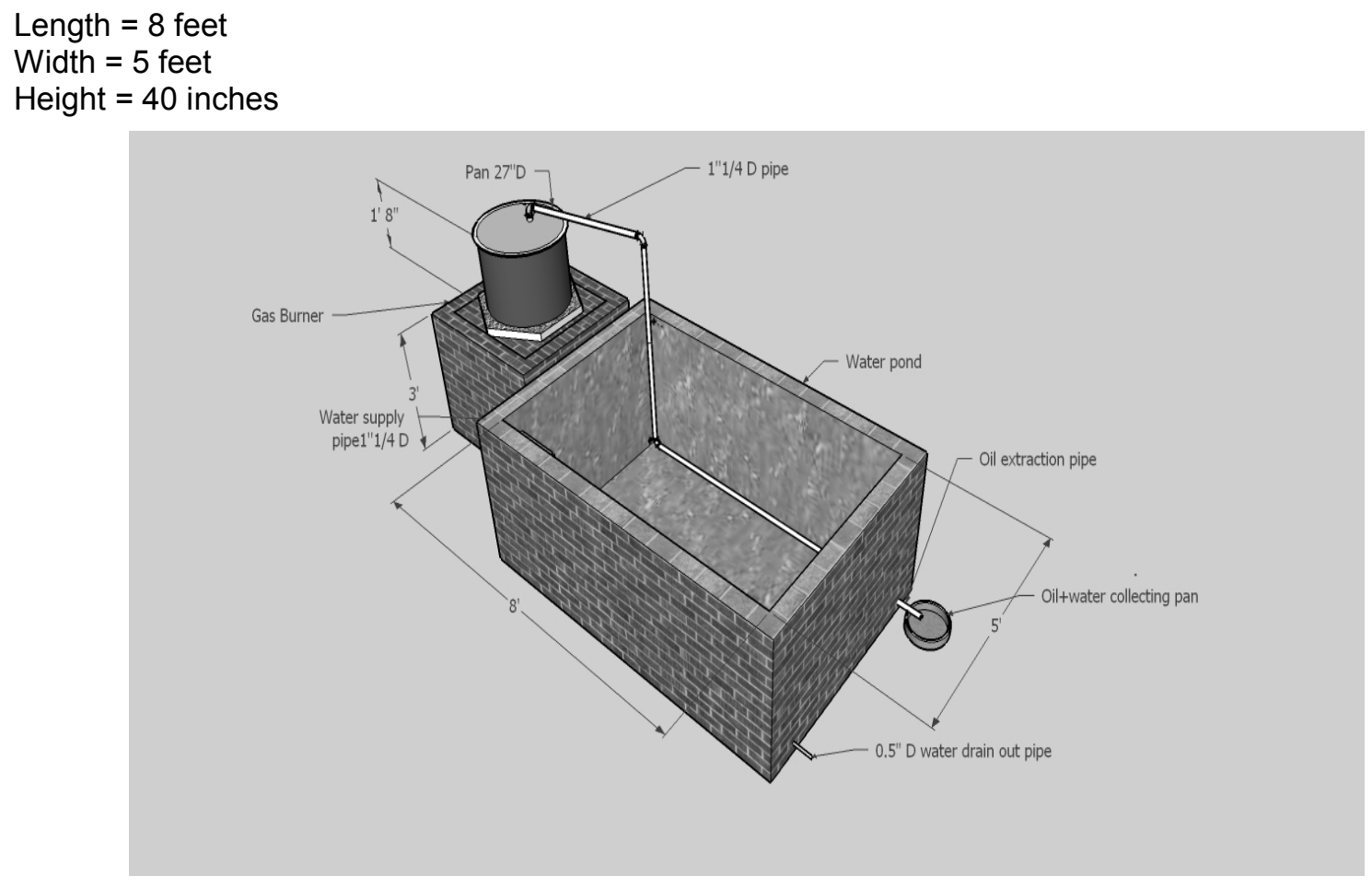

Fig. 1. Agarwood oil extraction chamber 


\section{Heating}

Fermented agarwood was divided into two equal parts, each of $7.5 \mathrm{~kg}$ and heated by a gas burner in two sessions.

\section{Condensation}

Ice was added to the condensation chamber water to cool the steam passing through steel pipe to the collection pan. Amount of ice and temperature of water is shown in the Table 1.

Table 1. Amount of added ice and corresponding water temperature

\begin{tabular}{|c|c|c|c|}
\hline \multirow{2}{*}{ Session } & \multirow{2}{*}{ Amount of ice $(\mathrm{kg})$} & Wefore addition & After addition \\
\cline { 3 - 4 } & 8 & 25 & 18 \\
\hline 1 & 5 & 24.5 & 20 \\
\hline 2 & & & $\left.{ }^{0} \mathrm{C}\right)$ \\
\hline
\end{tabular}

Amount measurement of extracted oil and remaining wood

Amount of collected oil was measured by a measuring cylinder and remaining wood was weighed after sun drying.

\section{Yearly Cost and benefit calculation}

Total yearly production cost was calculated by equation (1).

Total cost $=D+W_{c}+L_{c}+T_{c}+F_{c}+O \& M$

Here, $\mathrm{D}=$ annual depreciation of the extraction chamber $=\frac{\text { PurchasePrice }(T k)-\text { Selling price }(T k)}{\text { timebetween buyingandselling }(\mathrm{yr})}$;

according to Hunt (1995); $\mathrm{W}_{\mathrm{c}}=$ price of wood, $\mathrm{L}_{\mathrm{c}}=$ labour cost, $\mathrm{T}_{\mathrm{c}}=$ transport cost and $\mathrm{F}_{\mathrm{c}}=$ fuel cost

Yearly benefit and cost-benefit ratio were calculated by equation (2) and (3).

Benefit $=$ Total income - Total cost

Benefit-cost ratio $=\frac{\text { Benefit }}{\text { Total Cost }}$

Yearly income was calculated on the basis of agarwood oil and by-product wood's market price which existed during the period of experiment.

\section{Results and Discussion}

\section{Amount of oil and wood}

A total of $7 \mathrm{ml}$ oil was extracted from $15 \mathrm{~kg}$ agarwood. Amount of by-product wood (raw material of incense stick) was $12 \mathrm{~kg}$.

\section{Cost and benefit}

According to Bay of Bengal Perfumery Product Ltd. and Bismillah Agar Oil producer Company Ltd. Borolekha, Moulvibazar, Bangladesh. the price of agar oil and the by-product of agar wood were Tk. 624 per $\mathrm{ml}$. and Tk. 25 per kg. respectively. The findings of the present experiment and assuming uniform production and cost, calculation exhibited that yearly production cost and benefit were Tk 2,33,600 and $7,78,389$, respectively. Benefit-cost ratio was found as 2.33 . Total cost, income, benefit and benefit-cost ratio are shown in Table 2 and Table 3 respectively. 
Table 2. Yearly total cost

\begin{tabular}{|l|l|l|}
\hline Price of wood & Tk. $67 / \mathrm{kg}$ & Tk.167,500 \\
\hline Labor cost & Tk. 4500/month & Tk.54000 \\
\hline Transport cost & Tk. 5000 & Tk.5000 \\
\hline Fuel cost & Tk.450/month & Tk.5400 \\
\hline Depreciation cost of chamber & Tk.1200 tk. & Tk.1200 \\
\hline Operation and Maintenance cost & Tk. 500 500 \\
\hline \multicolumn{2}{|c|}{ Total } & Tk.2,33,600 \\
\hline
\end{tabular}

Table 3. Amount of income, benefit and benefit-cost ratio

\begin{tabular}{|c|c|c|}
\hline Total Income per year (Tk.) & Benefit (Tk.) & Benefit-cost ratio \\
\hline $7,78,389$ & $5,44,789$ & 2.33 \\
\hline
\end{tabular}

\section{Conclusion}

In Bangladesh contemporary agarwood oil extraction processes are very complex, comprising of expensive mechanical, solvent extraction and cold processing system. In this context, the developed hydro distillation method is much more suitable for the cultivators of Bangladesh economically and technologically. In traditional systems big investment is required for installation of extraction chamber. But this developed hydro-distillation method can bring yearly benefit of Tk 7,78,389 where the benefit-cost ratio is 2.33. Therefore, this developed oil extraction system is very prospective for agar tree growers and agarwood oil traders of Bangladesh.

\section{References}

Akter, S., Islam, M.T., Zulkefeli, M., Khan, S. I. 2013. Agarwood production- a multidisciplinary field to be explored in Bangladesh, International Journal of Pharmaceutical and Life Sciences, 2(1): 22-32.

Barden, A., Awang Anak, N., Mulliken, T., Song, M. 2000. Heart of the matter: agarwood use and trade and CITES implementation for Aquilaria malaccensis. TRAFFIC International, Cambridge, pp. 1-52.

Broad, S. 1995. Agarwood harvesting in Vietnam, TRAFFIC Bulletin, 15: 96.

Gibson, I.A.S. 1977. The role of fungi in the origin of oleoresin deposits (Agaru) in the wood of Aquilaria agallocha Roxb., Bano Biggyan Patrika. 6(1): 16-26.

Hunt, D. 1995. Farm power and machinery management- $9^{\text {th }}$ edition. lowa State University Press, Ames, lowa, USA.

Ng, L. T., Chang, Y. S. and Kadir, A. A. 1997. A review on agar (gaharu) producing Aquilaria species, Journal of Tropical Forest Products, 2(2): 272-285.

Oldfield, S, Lusty, C. and MacKinven, A. 1998. The Word List of Threatened Trees. World Conservation Press, Cambridge, UK, p. 650. 